\title{
Effects of $\alpha$-glucosidase inhibitors on mouth to caecum transit time in humans
}

\author{
S D Ladas, A Frydas, A Papadopoulos, S A Raptis
}

\begin{abstract}
The $\alpha$-glucosidase inhibitors acarbose and miglitol have been successfully used to control postprandial hyperglycaemia in diabetics. They probably work by slowing carbohydrate digestion and absorption, but their effect on mouth to caecum transit time has not been studied. The effect of acarbose $(100 \mathrm{mg})$, miglitol (100 $\mathrm{mg}$ ), and placebo on mouth to caecum transit time $(380$ kcal breakfast with $20 \mathrm{~g}$ of lactulose) was investigated in 18 normal volunteers using breath hydrogen analysis. Both miglitol and acarbose significantly increased breath hydrogen excretion $\left(F_{2,34}=6.31, p=0.005\right)$ and shortened the mouth to caecum transit time $\left(F_{2,34}=3.49\right.$, $\mathrm{p}=0.04$ ) after breakfast compared with placebo. There was a significant negative correlation between breath hydrogen excretion and mouth to caecum transit time suggesting that with shorter transit times significantly more carbohydrates were spilled into the colon. These results indicate that $\alpha$ glucosidase inhibitors accelerate mouth to caecum transit time by inducing carbohydrate malabsorption.
\end{abstract}

(Gut 1992; 33: 1246-1248)

BAY g 5421 (acarbose) and BAY m 1099 (miglitol) are competitive inhibitors of small intestinal $\alpha$-glucosidase. Acarbose is a pseudotetrasaccharide and has been used in clinical trials with insulin dependent and non-insulin dependent diabetes to control hyperglycaemia, improve the diabetic metabolic condition, and, if possible, to reduce the insulin requirements. ${ }^{12}$ Miglitol is a new $\alpha$-glucosidase inhibitor with the chemical structure of a 1-desoxynojirimycin. It has already been used in a few clinical trials in normal volunteers and diabetics. ${ }^{3+}$

Though intestinal $\alpha$-glucosidase inhibitors interfere with sucrose and starch digestion, ${ }^{5}$ glucose absorption is not affected. ${ }^{6}$ This slowing of carbohydrate digestion, and therefore of glucose absorption, caused by $\alpha$-glucosidase inhibitors has a beneficial effect in the treatment of diabetes mellitus. ${ }^{1-4}$ It does, however, result in a considerable degree of carbohydrate spilling into the colon ${ }^{7}$ that stimulates bacterial fermentation causing flatulence and occasionally diarrhoea. ${ }^{8}$ It is logical to hypothesise that the incomplete small intestinal carbohydrate absorption, by increasing the flow rate of the luminal contents, ${ }^{7}$ may stimulate peristalsis and shorten the small bowel transit time. However, to the best of our knowledge, this has never been investigated.

Thus, the objective of the present study was to investigate the effects of acarbose and miglitol on mouth to caecum transit time (MCTT).

\section{Methods}

\section{SUBJECTS}

Eighteen healthy male volunteers ${ }^{9}$ aged 18-40 years (mean (SD) $30.3(6.5)$ years) participated in the study. All were of normal body weight, taking a normal diet, and had a normal bowel habit. None had symptoms or a history of gastrointestinal disease or surgery or had received antibiotics in the two months before the study. Written informed consent was obtained from all individuals tested. The protocol of the study was approved by the Ethical Committee on Human Studies of the Department of Internal Medicine, University of Athens, in October 1985.

\section{TEST MEAL}

The breakfast used to measure MCTT consisted of two slices of toast (17 g), butter (15 g), marmalade ( $20 \mathrm{~g})$, one hard boiled egg, and 200 $\mathrm{ml}$ of weak tea containing $20 \mathrm{~g}$ of lactulose $(30 \mathrm{ml}$ of Duphalac, Duphar, Southampton, UK) and $10 \mathrm{~g}$ of sucrose. The complete meal contained $380 \mathrm{kcal}$. Forty two per cent of the calories were derived from carbohydrate, $10 \%$ from protein, and $48 \%$ from fat. Since the prevalence of incomplete lactose digestion in Greece is $75 \%,{ }^{10}$ milk was not included in the breakfast. The amount of lactose $(2.4 \mathrm{~g})$ contained in $30 \mathrm{ml}$ of Dulphalac has been shown not to affect breath hydrogen excretion. ${ }^{11}$ This meal has been previously tested and proved to produce reproducible MCTT measurements. "

\section{MCTT AND CARBOHYDRATE ABSORPTION STUDY}

These were investigated in a placebo controlled, double blind, randomised, three fold, cross over study with complete block design experiments. Each volunteer was studied three times. The washout periods were seven days. Acarbose (BAY g 5421) and miglitol (BAY m 1099) (Bayer AG, Leverkusen, Germany) were supplied as $100 \mathrm{mg}$ tablets. The tablets and placebo were identical in size, shape, and colour and were distributed in cellophane bags labelled with each subjects random number and test day. The amount of lactose contained in the tablets was negligible $(120 \mathrm{mg})$. They were swallowed half an hour before the ingestion of the test meal. After an overnight fast (10-12 hours), the volunteer consumed the test meal within 15 minutes. The breath hydrogen concentration 
was measured at $-60,-30$, and 0 minutes and at 10 minute intervals thereafter, over a four hour period.

End expiratory breath samples were collected in $50 \mathrm{ml}$ polyethylene syringes, while the volunteer exhaled through a modified HaldanePriestley tube, ${ }^{12}$ and the $\mathrm{H}_{2}$ concentration was measured by a research chromatograph (Hewlett-Packard 5750G) equipped with a thermal conductivity detector. The operating conditions have been published elsewhere. ${ }^{10}$ The minimum hydrogen concentration detectable was $3 \mathrm{ppm}$, which gave a recorder deflection of $2 \mathrm{~mm}$.

A breath hydrogen concentration $\geq 20 \mathrm{ppm}$ over the baseline was taken as indicating the arrival of lactulose and/or malabsorbed carbohydrate into the caecum. MCTT was therefore defined as the interval between finishing the meal and the first of two sequential increases in breath hydrogen concentration $\geq 20 \mathrm{ppm}$ over the base line. If after four hours no such a rise in breath hydrogen occurred, the transit time was recorded as 240 minutes. ${ }^{13}$

\section{CALCULATIONS AND STATISTICS}

The area under the breath hydrogen curve was calculated using the trapezoid rule. ${ }^{14}$ is Results in the text and figures are presented as mean (SEM). The statistical significance of the results was assessed by randomised blocks analysis of variance (ANOVA) and paired $t$ test as appropriate. ${ }^{16}$ Correlation between breath hydrogen excretion and MCTT was evaluated by regression analysis and comparisons between slopes and correlation coefficients by covariance analysis. ${ }^{16}$ Probabilities of $<0.05$ were regarded as significant.

\section{Results}

All volunteers (n:18) ate the breakfast within 15 minutes and found it palatable. Non-hydrogen producers were not encountered in this study, since all volunteers excreted $\geq 20 \mathrm{ppm}$ of breath hydrogen in at least one of the experiments after eating the breakfast marked with lactulose.

Treatment significantly affected MCTT (randomised blocks ANOVA: $\mathrm{F}_{2,34}=3 \cdot 49, \mathrm{p}=$ 0.042 ). This effect was due to the shorter MCTT after miglitol (107 (14) minutes) as well as after acarbose (106 (13)) in comparison with placebo (139 (18) minutes), (paired $t=2 \cdot 16, \mathrm{p}=0.023$ and paired $t=1.98, \mathrm{p}=0.032$ respectively).

The mean breath hydrogen curves after acarbose, miglitol, and placebo are shown in Figure 1. Significantly more hydrogen was excreted after acarbose $(122.56(14.67))$ or miglitol $(112.67(18.91))$ than in placebo experiments $\left(74.00(11.40)\right.$ ppm. 4 hours, $F_{2,34}=6.31$, $\mathrm{p}=0.005)$. When individual breath hydrogen excretion was plotted against MCTT (Fig 2), there was a significant negative log-linear correlation between the two variables after acarbose $(\mathrm{Y}=5.92-0.013 \mathrm{x}, \quad \mathrm{r}=-0.91, \quad \mathrm{~T}=-8.75$, $\mathrm{p}<0.001)$, miglitol $(\mathrm{Y}=5.83-0.013 \mathrm{x}, \mathrm{r}=-0.86$, $\mathrm{T}=-6.68, \mathrm{p}=0.001)$, and placebo $(\mathrm{Y}=5.33$ $0.009 x, r=-0.91, T=-9.02, p<0.001)$. The slopes of the regression lines, as well as the

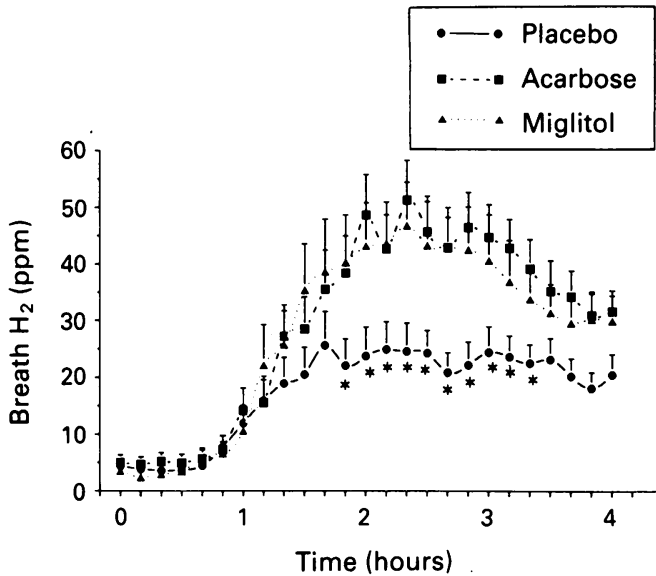

Figure 1: Breath hydrogen response to breakfast $(380 \mathrm{kcal})$ marked with $20 \mathrm{~g}$ of lactulose after acarbose $(100 \mathrm{mg})$, miglito $(100 \mathrm{mg})$, and placebo. Values of 18 normal volunteers are given as mean $(S E M)$. ${ }^{\star}$ Differences between treatment groups and placebo are significant (randomised blocks ANOVA, $p<0.02-0.003)$.

correlation coefficients of acarbose and placebo did not differ significantly $\left(F_{1,32}=3 \cdot 57, F_{16,16}=\right.$ 1.01 respectively, $p>0.05)$, nor did those of miglitol and placebo $\left(F_{1,32}=3 \cdot 55, F_{16,16}=2 \cdot 07\right.$, $\mathrm{p}>0 \cdot 10)$.

\section{Discussion}

This is the first published report on the effects of $\alpha$-glucosidase inhibitors on MCTT. Our results indicate that after ingestion of a solid-liquid meal (breakfast) miglitol and acarbose at a dose of 100 mg induce carbohydrate malabsorption and therefore shorten the MCTT. These results agree with those of a preliminary study of eight normal subjects given $200 \mathrm{mg}$ of acarbose after a $380 \mathrm{kcal}$ breakfast, where we had also observed a significant acceleration of MCTT in comparison with placebo. ${ }^{17}$ The negative correlation we have found between MCTT and breath $\mathrm{H}_{2}$ excretion suggests that with shorter transit times more carbohydrates are spilled into the colon. This is

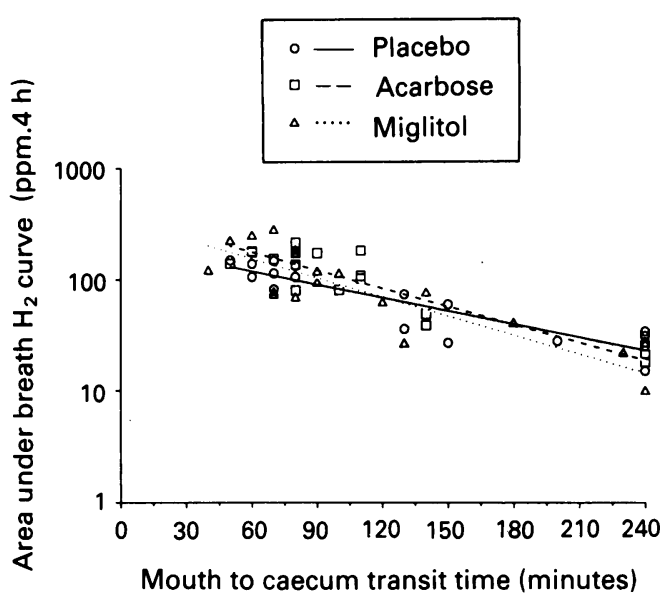

Figure 2: Correlation of individual breath hydrogen excretion (log scale) and mouth to caecum transit time (MCTT) after ingestion of breakfast ( $380 \mathrm{kcal}$ ) marked with $20 \mathrm{~g}$ of lactulose. Correlations with regard to acarbose $(100 \mathrm{mg})$, miglitol (100 mg), and placebo are significant $(r=-0.91$ $r=-0.86, r=-0.91$ respectively, $p<0.001$ ) 
compatible with experiments in normal subjects ingesting increasing doses of lactulose, where an inverse relation between carbohydrate malabsorption and MCTT has been shown. ${ }^{18}$ Though the inhibition of absorption induced by the $\alpha$-glucosidase inhibitors is the primary phenomenon, under the present experimental conditions, it is not possible to estimate whether the acceleration in the intestinal transit time contributes to carbohydrate malabsorption by reducing the contact time between the intestinal contents and small intestinal mucosa. However, it is known from ileal intubation studies that acarbose may induce carbohydrate malabsorption of up to $50 \%$ of the ingested carbohydrate, ${ }^{7}$ and that glucose absorption is least efficient from the most rapidly moving front of an ingested bolus of glucose. ${ }^{19}$ Despite this evidence, one cannot preclude the possibility that the $\alpha$ glucosidase inhibitors produce their effect solely by inhibiting absorption and that the acceleration of MCTT is a secondary phenomenon, more or less irrelevant to the percent absorption. It may also be argued that the negative correlation we have found between breath $\mathrm{H}_{2}$ excretion and MCTT was due to the lactulose taken with the breakfast. However, Rumessen et al did not observe significant changes with regard to the area under breath $\mathrm{H}_{2}$ excretion curves, compared for the same dose of lactulose despite significant changes in MCTT induced by metoclopramide. ${ }^{18}$

Studies published to date assume that $\alpha$ glucosidase inhibitors exert their control on postprandial hyperglycaemia by delaying carbohydrate absorption from the small intestinal lumen. ${ }^{1-462021}$ However, as we have shown, $\alpha$ glucosidase inhibitors accelerate MCTT by inducing carbohydrate malabsorption. This unquestionable carbohydrate malabsorption, ${ }^{7}$ leads to a pronounced change in colonic function and metabolism by stimulating bacterial proliferation. ${ }^{82}$ Malabsorbed polysaccharides are fermented to short chain fatty acids which are rapidly absorbed from the colon in humans, ${ }^{23}$ providing $90-240 \mathrm{kcal} /$ day in normal subjects that is, $5-10 \%$ of daily energy requirements. ${ }^{2+25}$ Thus, in patients with carbohydrate malabsorption the colon may play an important role in meeting total energy needs. Furthermore, fermentation does not increase the colonic osmotic pressure and diarrhoea is not longer considered to occur as a side effect since most of this osmotic load is rapidly absorbed. ${ }^{26}$

In conclusion, $\alpha$-glucosidase inhibitors, by inducing carbohydrate malabsorption, accelerate MCTT. We speculate that the beneficial effect on blood glucose concentrations of $\alpha$-glucosidase inhibitors, is mediated by small intestinal carbohydrate malabsorption, compensated by colonic short chain fatty acid absorption as an alternative source of energy.
I Walton RJ, Sherif IT, Noy GA, Alberti KGMM. Improved metabolic profiles in insulin-treated diabetic patients given an alpha-glucosidehydrolase inhibitor. BMf 1979; 1: 220-1.

2 Sachse G, Willms B. Effect of the $\alpha$-glucosidase inhibitor acarbose on blood glucose control of sulphonyl-urea-treated diabetics and insulin-treated diabetics. Diabetologia 1979; 14: $287-90$.

3 Dimitriadis G, Raptis S, Raptis A, Hatziagelaki E, Mitrakou $A$, Halvatsiotis P, et al. Effects of two new $\alpha$-glucosidase inhibitors on glycemic control in patients with insulindependent diabetes mellitus. Klin Wochenschr 1986; 64: 405-10.

4 Dimitriadis G, Hatziagelaki E, Ladas S, Linos A, Hillebrand I, Raptis S. Effects of prolonged administration on two new $\alpha$-glucosidase inhibitors on blood glucose control, insulin requirements and breath hydrogen excretion in patients with insulin-dependent diabetes mellitus. Eur f C lin Invest 1988 18: 33-8.

5 Puls W, Keup V, Krause.HP, Thomas G, Hoffmeister F. Glucosidase inhibition: a new approach to the treatment of diabetes, obesity and hyperlipoproteinaemia. Naturwissenschafter 1977; 64: 536 .

6 Jenkins DJA, Taylor RH, Goff DV, Fielden H, Misiewicz JJ, Sarson DL, et al. Scope and specificity of acarbose in slowing carbohydrate absorption in man. Diabetes $1981 ; 30$ : $951-4$.

7 Ruppin H, Hagel J, Feuerbach W, Schutt H, Pichl J, Hillebrand I, et al. Fate and effects of the $\alpha$-glucosidase inhibitor acarbose in humans. Gastroenterology 1988; 95: 93-9.

8 Scheppach W, Fabian C, Ahrens F, Spengler M, Kasper H. Effect of starch malabsorption on colonic function and metabolism in humans. Gastroenterology 1988; 95: 1549-55.

9 Wald A, Van Thiel DH, Hoechstetter L, Gavaler JS, Egler $\mathrm{KM}$, Verm R, et al. Gastrointestinal transit: The effect of the menstrual cycle. Gastroenterology 1981; 80: 1495-500.

10 Ladas S, Papanikos J, Arapakis G. Lactose malabsorption in Greek adults; correlation of small bowel transit time with the Greek adults; correlation of small bowel transit time with

11 Ladas SD, Latoufis C, Giannopoulou H, Hatziioannou J, Raptis SA. Reproducible lactulose hydrogen breath test as a measure of mouth-to-cecum transit time. Dig Dis Sci 1989 34: 919-24.

12 Metz G, Gassull MA, Leeds AR, Blendis LM, Jenkins DJA A simple method of measuring breath hydrogen in carbohydrate malabsorption by end-expiratory sampling. Clin $S$ Mol Med 1976; 50: 237-40.

13 Lawson M, Kern F Jr, Everson GT. Gastrointestinal transit time in human pregnancy: Prolongation in the second and the third trimesters followed by postpartum normalization. Gastroenterology 1985; 89: 996-9.

14 Daniels F. Mathematical preparation for physical chemistry. New York: McGraw-Hill, 1956.

15 Welsh JD, Payne DL, Manion C, Morrison RD, Nichols MA. Interval sampling of breath hydrogen $\left(\mathrm{H}_{2}\right)$ as an index of lactose malabsorption in lactase-deficient subjects. Dig Dis Sci 1981; 26: 681-5.

16 Armitage P, Berry G. Statistical methods in medical research 2nd ed. Oxford: Blackwell Scientific Publications, 1987.

17 Ladas SD, Latoufis C, Rokkas T, Hatzioannou J, Dimitriadis G, Raptis SA. Effect of acarbose on mouth to caecum transit time in normal man. Diabetes Res Clin 1985; 1 (suppl): S325.

18 Rumessen JJ, Hamberg O, Gudmand-Hoyer E. Influence of orocaecal transit time on hydrogen excretion after carbohyorocaecal transit time on hydrogen excretion

19 Bond JH, Levitt MD. Use of breath hydrogen to quantitate small bowel transit time following partial gastrectomy. $\mathcal{F} \mathrm{Lab}$ Clin Med 1977; 90: 30-6.

20 Radzink J, Kemmer F. Quantitation of the effects of the $\alpha$ glucosidase inhibitor, acarbose, on the hydrolysis and absorption of sucrose and hormone responses in man. Diabetologia 1981; 21: 318-21.

21 Puls W, Keup U, Krause HP, Thomas G, Hoffmeister F. The concept of glucosidase inhibition and its pharmacological realization. In: Creutzfeldt W, ed. Acarbose: effects on carbohydrate and fat metabolism. Amsterdam: Excerpta Medica, 1981: 11-6.

22 Shimoyama T, Hori S, Tamura $\mathrm{K}$, Tamida N, Hosomi $\mathrm{H}$ Wad M. Effects of acarbose on faecal microflora of hyperlipidaemic patients. In Creutzfeldt W, ed. Acarbose: Effects on carbohydrate and fat metabolism. Amsterdam: Excerpta Medica, 1981: 123-36.

$23 \mathrm{McNeil}$ NI, Cummings JH, James WPT. Short-chain fatty acid absorption by the human large intestine. Gut 1978; 19: $819-22$.

$24 \mathrm{McNeil}$ NI. The contribution of the large intestine to energy supplies in man. Am f Clin Nutr 1984; 39: 338-42.

25 Royall D, Wolever TMS, Jeejeebhoy KN. Clinical significance of colonic fermentation. Am $\mathcal{F}$ Gastroenterol 1990; 85: 1307-12.

26 Bond JH, Levitt MD. Effect of dietary fiber on intestinal gas production and small bowel transit time in man. $A m \mathcal{F}$ Clin Nutr 1978; 31: S169-74. 